\title{
Erratum to: Breast and cervical cancers diagnosed and stage at diagnosis among women served through the National Breast and Cervical Cancer Early Detection Program
}

\author{
Jacqueline W. Miller ${ }^{1} \cdot$ Janet Royalty $^{1} \cdot$ Jane Henley $^{1} \cdot$ Arica White $^{1} \cdot$ \\ Lisa C. Richardson ${ }^{1}$
}

Published online: 30 April 2015

(c) Springer International Publishing Switzerland 2015

\section{Erratum to: Cancer Causes Control DOI 10.1007/s10552-015-0543-2}

In the original publication of the article, references 19, 22 and 23 have not been cited properly. The corrected references are given below.

\section{References}

19. Wu M, Austin H, Eheman CR et al (2015) A comparative analysis of breast cancer stage between women enrolled in the
National Breast and Cervical Cancer Early Detection Program and women not participating in the program. Cancer Causes Control. doi:10.1007/s10552-015-0548-x

22. Tangka FKL, Howard D, Royalty J et al (2015) Cervical cancer screening of underserved women in the United States: results from the National Breast and Cervical Cancer Early Detection Program, 1997-2012. Cancer Causes Control. doi:10.1007/ s10552-015-0524-5

23. Howard D, Tangka FKL, Royalty J et al (2015) Breast cancer screening of underserved women in the United States: results from the National Breast and Cervical Cancer Early Detection Program, 1998-2012. Cancer Causes Control. doi:10.1007/ s10552-015-0553-0
The online version of the original article can be found under doi:10. 1007/s10552-015-0543-2.

Jacqueline W. Miller

JMiller5@cdc.gov

1 Division of Cancer Prevention and Control, National Center for Chronic Disease Prevention and Health Promotion, Centers for Disease Control and Prevention, 4770 Buford Hwy NE, Mailstop F-76, Atlanta, GA 30341, USA 